\title{
Considering time in climate justice
}

\author{
Judith Bopp $^{1}$ and Anna Lena Bercht ${ }^{2}$ \\ ${ }^{1}$ Institute for Spatial Analysis and Planning in Areas of Intensive Agriculture (ISPA), University of Vechta, \\ 49377 Vechta, Germany \\ ${ }^{2}$ Department of Geography, Kiel University, \\ Ludewig-Meyn-Str. 14, 24098 Kiel, Germany
}

Correspondence: Judith Bopp (judith.bopp@uni-vechta.de) and Anna Lena Bercht (bercht@geographie.uni-kiel.de)

Received: 2 April 2020 - Revised: 5 January 2021 - Accepted: 7 January 2021 - Published: 26 February 2021

\begin{abstract}
Time shapes every single human-environment relationship and is inherent in 21st-century global challenges such as climate change and the urgent move towards global sustainability. Nonetheless, the concept of time is still insufficiently addressed in climate justice debates. This paper aims to help fill this gap by presenting empirical results about experiences of climate change in farming communities in Tamil Nadu, South India, and fishing communities on the Lofoten Islands, Norway. With the help of the five dimensions of affectedness, rhythms and rituals, slow motion, care, and health and well-being, it exemplifies how time matters to issues of climate injustices faced by the communities. The paper promotes a qualitative understanding of time and climate change. Thereby, it may stimulate greater relatability to climate change, as well as discussion likely to lead to conceptual advances.
\end{abstract}

\section{Introduction}

The issue of time has always been an issue of interest to human beings, though certainly with ever-changing aspects, aspirations and narratives. It is a rich topic not only in the social and natural sciences and the humanities but also in spirituality, religion, culture, the arts and - of course - people's everyday life (for more details see Atmanspacher and Ruhnau, 1997; Meister and Schernus, 2011). A vast amount of academic and non-academic literature has addressed and controversially discussed ontologies of time and various related aspects such as temporality, irreversibility, velocity, eternity, transience and the now (e.g. Grosz, 2004; Bercht, 2013). Despite this long-standing dedication to the subject in thought and practice, time remains ontologically difficult to grasp. Yet, time as a concept is essential as we all exist in time. Without time, there is no movement, transformation or orientation, causality, meaning-making, or memory - but there is also no climate change, adaptation or, as this paper further illustrates, injustice. It is beyond the scope of this paper to prolong this argument (for the various conceptualisations and definitions of time cf. e.g. Brann,
1999; Bardon and Dyke, 2013). However, time shapes the life of every single human being, assuming that the continued progress of human physical existence occurs in an (apparently irreversible) succession from the past through the present into the future. Furthermore, based on the premise that humans do not act in isolation but are rather dialectically interwoven with their social, cultural, political, economic and ecological environments (cf. Bercht, 2013; Hastrup and Robow 2014a, b; Hutchison, 2015), every single human-in-environment relationship is shaped by dimensions of time, as will become clear in the case studies below. From this viewpoint, the global 21 st-century challenges, such as climate change, shrinking biodiversity and food insecurity, and their dynamics cannot be fully explored without taking dimensions of time into consideration. Configurations of humans and their environments are continuously in flow and are permanently produced and reproduced through interaction. People bring about and shape change, which is inherently linked to time dimensions, whether at a slow or a fast pace. They also live with change. For example, activities are guided by seasonal changes and well-known rhythms: when 
the rainy season comes, it is time for planting; when the ocean gets warmer in spring, it is time for fish hunting.

One aspect in the debate on global 21 st-century challenges that has received insufficient attention is the explicit role of time in analysing how justice- and injustice-related issues emerge from or are linked to these challenges (Tamoudi and Reder, 2019). Can a time lens make certain things visible (and therefore available for resolving injustices) which would otherwise remain hidden, unexplored and unresolved? The concept of climate justice has gained momentum in recent years thanks to growing recognition that climate change is also an ethical issue (Gardiner, 2011; cf. Schlosberg and Collins, 2014, on the conceptual expansion of environmental justice to climate justice), since climate change adversely affects basic human rights of life such as the right to justice, health, well-being and subsistence (Adger et al., 2013; Caney, 2006; Gach, 2019). The impacts of climate change will affect and are already affecting some communities more and earlier than others, depending on their exposure to climate change in time and space. As another aspect of injustice, the top contributors to greenhouse gas emissions, such as China, the USA and Germany, are, broadly speaking, unlikely to be among the earliest affected or the most vulnerable (Agyeman et al., 2016).

Our work with climate-induced change in farming communities in Tamil Nadu, South India, and fishing communities on the Lofoten Islands, Norway, combined with Gordon Walker's call for time to be considered in environmental and climate justice narratives during his keynote speech at the workshop "Narratives and practices of environmental justice" (Kiel University, Germany, 6-8 June 2019) inspired us to apply a time lens to our case studies. The aim was to distil the relations between time and climate justice contained in our research. Given that our work in India and Norway took root in different projects and evolved independently of each other using different but similar methodologies (cf. Sect. 3.2), it was never our intention to compare across the Global North and Global South. Rather, the focus of this paper is to illustrate that the communities, which are particularly affected by climate change, display multiple facets of time that interweave the local settings with the farmers' and fishers' practices and routines and their affectedness by and responses to climate change. To reveal these multiple facets, we provide a qualitative understanding of the time inherent in our case studies, which shapes and determines various climate injustices. With reference to Neimanis and Walker (2014), such a qualitative understanding could imply a "new imaginary" (p. 559) of climate change. This may bridge the abstraction often prevalent in scientific climate change discourses and lead instead to a rethinking of climate change as a "transcorporal, intra-active phenomenon" (p. 560) of human bodies and climate. In this transcorporal understanding of human-climate interaction, human bodies are entwined with non-human natures such as weather and climate, thereby becoming makers of climate change.
This understanding implies that "we are thick with climatic intra-action" (p. 558). Hence as humans we veritably live and co-produce the climate. This is where the aspect of time comes in: living the climate conveys that we are not only spatially but also temporally in it. To put it in Neimanis and Walker's (2014) words, "climates and weather are not something we pass through [...] but are rather a time that we weather together" (p. 570). In line with this, Brace and Geoghegan (2010) criticise that climate change discourses typically give much thought to "scientific epistemologies" and "measurement regimes", while leaving "relatively unchallenged the idea that climate change is [itself] the thing that explains" (p. 285).

Against this backdrop, this paper aims to demonstrate the necessity and benefits for scholars and practitioners alike to consider different notions and experiences of time in climate justice debates. Pertinent examples here include climate adaptation and transformations to sustainability, including e.g. institutional reforms and fundamental shifts in thinking, social norms, values, attitudes and behaviour necessary to enable sustainable futures to emerge (cf. O'Brien, 2012). It is suggested that scientifically produced climate justice discourses may increasingly attend to temporalities experienced by people in vulnerability settings in their daily lives (Arnall and Kothari, 2015). Drawing on evidence from our two case studies, but without comparing them, we exemplify how climate change exposes uneven vulnerabilities and injustices related to the issue of time with the help of five dimensions through which time becomes apparent: affectedness, rhythms and rituals, slow motion, care, and health and well-being. Derived from our data, we chose these five dimensions to illustrate aspects of time. Further, in our case studies we discovered three overlapping forms of time interacting with settings and people's practices, and their potential responses to climate change. Based on reflection of our results, we define these as "world time", "micro-time" and "natural time" (cf. Sect. 4.2). This paper attempts to serve as a starting point for discussion of the relationship between time and climate justice. Which hidden dimensions of time may be beyond the linear external dimension that usually feeds the scientifically produced discourses that are utilised, for instance, by the IPPC (Intergovernmental Panel on Climate Change; cf. Arnall and Kothari, 2015)? What is the role of laypersons' experiences of and participation in time, especially in vulnerability settings? And how can awareness of these experiences explain and eventually help counter climate injustices? The discussion is intended to inspire environmental and climate justice research and practice through the inclusion of an underexplored qualitative framing of time and multiple dimensions of time relevant to climate change and climate justices. 


\section{Time in climate change and climate justice literature}

A large body of work explores climate change with regard to a range of related issues such as affectedness, rhythms and rituals, slow motion, care, and health and well-being. These are issues that this paper also elaborates upon. The following cited literature provides a non-exhaustive but representative account of research in this field. For example, the point of different levels of climate affectedness is central to a study by Meyer-Ohlendorf (2019) on heat waves, strong rain events and flooding in urban India. Changes in seasonality under the influence of climate change have been discussed with respect to resource management and agriculture (Feng et al., 2013; Van Loon et al., 2014). Focusing on the issue of rhythms and rituals, Gumo (2017) examines how indigenous knowledge in rainmaking rituals, determined by the natural rhythm of the seasons, helps Kenyan communities to respond to climate change. Pilkey and Pilkey (2019), in contrast, analyse the effects of 21st-century sea-level rise, which they describe as a "slow-motion tsunami" (p. xi), on the US shoreline. Moreover, looking at the dimension of care, FitzGerald et al. (2019) explore how to prepare Australian health care systems for climate-related disasters and emergencies. And, on a more global and general level, Watts et al. (2015) map out climate change risks and the policy responses necessary to ensure the highest attainable standards of health and well-being for populations worldwide. Also, it is important to note that, in addition to the aforementioned work by Gumo (2017), there are several studies that explicitly address the role of time in climate change contexts. For instance, Hastrup and Robow (2014b) illuminate how seasonal rhythms, histories, personal and collective memories, fears, and hopes are lived within multiple times and influence how people cope with manifest climate change. Hatfield et al. (2018) consider indigenous knowledge systems in possession of a profound sense for the "right moment $[\ldots]$ to act based on environmental indicators" (p. 9). From a rather theoretical viewpoint, Pahl et al. (2014) reflect upon sociological and psychological theories and findings on time perceptions in relation to climate adaptation and mitigation solutions. Further, from a philosophical perspective, the notion of time is fundamental to the idea of intergenerational environmental justice; i.e. generations by definition live in different time(s). In this regard, Reder et al. (2018) stress how different generations also live synchronically, in a "social relational structure" that "interconnects present lives with those in the future" (p. 285). In contrast to this, moral reasoning on the temporal effects of environmental hazards and, more generally, of climate change often distinguishes between immediate damage to current generations and long-term impacts on future generations, while overlooking the fact that people live for several generations to come (cf. Reder et al., 2018). In this vein, Winter (2020) advocates for the synchronicity of different generations to be considered in the intergenerational en- vironmental justice debates. The past always co-exists in the present - and the future in the past - just as identity is "simultaneously multiple identities" (p. 14). She supports her valuable argument through Māori ontologies of time which are "spirally bound" (p. 6) in contrast to Western ideas of a linear, forward-moving time.

Finally, to point to a geographical reference, Oppermann et al. (2020) appeal for engagement with rhythm analysis as an analytical tool to view "energetic-thermal flows" (p. 275) inherent to and surrounding bodies. Rhythm analysis was developed by Lefebvre and Régulier (1985) to elaborate the relationships between rhythmic flows and everyday life, whereby everyday life is crossed by "great cosmic and vital rhythms" (p. 191, authors' translation from French) such as seasons and biological rhythms of the human or nonhuman body. Natural rhythms can be subject to "technological or socio-economic" factors (p. 74), and the body through its metabolism becomes co-constitutive of rhythm. However, there is much scope in the academic climate literature to exploit the direct entanglement of climate change, time and concrete climate injustices which only or particularly become visible through a time lens. Even though some authors from the field of environmental and climate justice allude to aspects of time in the spatio-temporal formation of injustices (e.g. Walker, 2009), there has been no more substantive and in-depth discussion of the interface between time and climate justice. This would allow for the full range of potential climate injustices to be better captured and tackled.

Taking account of how environmental justice and later climate justice have emerged as concepts (Schlosberg, 2007; Walker, 2012) and considering the rich scientific debate on the different conceptual foundations of these concepts (White, 2004; Schlosberg and Collins, 2014; Holland, 2017; Newell et al., 2020; Nightingale, 2020), we focus on distribution, recognition and procedure as the core dimensions of environmental justice as developed by Schlosberg (2007) and Walker $(2009,2012)$. According to Walker (2009), distribution refers to the spatialities of the "unequal distribution of impacts" (p. 615) and responsibilities. Recognition describes "the processes of disrespect, insult and degradation that devalue some people and some place identities in comparison to others" (p. 615). And procedural justice refers to equality in consideration of groups in "environmental decision-making" (p. 615). These three aspects have become widely recognised among environmental justice scholars and practitioners (cf. Schlosberg and Collins, 2014; Agyeman et al., 2016; Fünfgeld and Schmid, 2020). In order to fully grasp and address the spatialities shaping the settings of both environmental and climate justice, Walker (2009) suggests embracing the various forms of spatialities that work "on different scales" (p. 615) in our thinking. Considering that inequalities exist through more than a spatial dimension of risk, it could be argued that the three aspects of distribution, recognition and procedure comprise an additional time factor: spatialities exist through time and therefore may encompass scales of time. 
In this light, it is beneficial to make these scales of time that define climate injustices more visible in the climate justice debates. Time can help clarify our spatio-temporal notions of the settings in which climate change affects people and can elucidate how situations of climate injustices occur and evolve in the future. Beyond that, time is embodied in timely reactions and appeals for adaptational strategies to climate change, as we further illustrate by our case studies.

\section{Smallholder farming in India and coastal fisheries in Norway}

Our call to take greater account of time in climate justice research and practice is exemplified using selected research data collected in rural areas in the Indian state of Tamil Nadu in 2017 and 2019 and in the fishing communities on the Lofoten Islands in the Norwegian Arctic in 2015. Both case studies share the challenge of being on the front lines of climate change and facing the particular harm and threat of changing weather patterns, modifications in terrestrial and marine food chains, and climate-induced uncertainty. As further illustrated below, the smallholders in Tamil Nadu and the Lofoten coastal fishers are particularly vulnerable, as their economic, cultural and social activities are closely connected to the natural environment and time-related socio-ecological processes such as the recurring harvest and fishing season.

\subsection{Background and the challenges ahead}

Tamil Nadu is the most southeastern state of India and has a population of about 72 million (as of the 2011 population census; Census 2011, 2020), of which about $40 \%$ rely on agriculture as their principal source of livelihood (as of 2013-2014; Government of Tamil Nadu - Department of Evaluation and Applied Research, 2020). Agriculture, however, is currently challenged by structural causes ranging from ecological to socio-economic to cultural-political (cf. Bopp, 2020). Rural and peri-urban farmers in Tamil Nadu are usually under the influence of the northeast monsoon, which brings seasonal rains from October to December, but now increasingly have to deal with the repercussions of climate change on local and global scales, which results in both minimal seasonal rainfall and excessive rains (ENVIS Centre, 2018, 2020).

Tamil Nadu's rainfed regions are particularly affected, since most farmers in these regions solely depend on the seasonal rains. Apart from general climate variability, trends in surface air temperature rise during the past decades can be observed, with average maximum temperatures between 29.8 and $33.6^{\circ} \mathrm{C}$ in 2014 , compared to 28.9 and $32.9^{\circ} \mathrm{C}$ in 1984 and to 28.2 and $32.2^{\circ} \mathrm{C}$ in 1954 , depending on altitude (Tamil Nadu Climate Change Knowledge Portal, 2020). Moreover, Tamil Nadu has been repeatedly struck by droughts resulting from the failure of monsoonal rains in alternation with floods due to an excess of rain and also a rising number of cyclones
(ENVIS Centre, 2018). Smallholder farming is reliant on non-polluted - natural resources: surface water or groundwater, intact soils, and agricultural diversity. This contrasts with the reality in the study area, where soils have widely degraded under the practice of monoculture, with the most common crop being rice, and the sustained use of agrochemicals. Soils widely lack fertile organic matter. Monsoon failure in combination with mismanagement increasingly leads to the pollution, lack of replenishment or complete disappearance of water bodies throughout the villages. Such destabilisation of farm ecosystems finally exacerbates the decline of yields and proneness to pests (cf. Bopp, 2020; Balasubramanian, 2015; interview with a rice farmer and founder of a local farmer network in Kumbakonam in 2019). This trend is now even multiplied under the effects of climate change in Tamil Nadu. Such effects include seasonally spiking temperatures and both inundations and enduring droughts, causing accelerated soil degradation and plant growth disruption (cf. also Hijioka et al., 2014, p. 1330). The use of or increase in agrochemicals is a common strategy among farmers who lack alternatives (cf. also Sect. 4.1 and Fig. 1). Low soil productivity is frequently countered by generously applying chemical fertilisers to ensure at least moderate yields, while the fear of losing potential harvests to pest outbreaks is combated by using pesticides. Analogously, socio-economic and cultural-political developments challenge smallholder farming in the study area. Urbanisation and industrialisation; class and cultural distinctions; and the limited power and scope for action of smallholder farmers, e.g. their low investment capacity and exposedness to unfavourable agricultural policies, determine smallholders' ecological and socio-structural environments, including households and livelihoods (cf. Fig. 1). Access to irrigation water, for instance from groundwater reservoirs, is unequally distributed. Constructing and operating the deep bore wells mostly requires financial power, and, furthermore, local authorities sometimes regulate water extraction or give priority to more powerful actors such as industries that smallholders then need to compete with.

This setting continues to challenge many Tamil Nadu smallholders, in the form of livelihood restraints and changing practices, routines, and professional trajectories, since many farmers shift to non-farming occupations. As a lateral effect, the farmers' health deteriorates under the long-term exposure to agrochemicals (field notes from 2017 and 2019; cf. Sect. 3.2).

The Lofoten Islands, our second case study, are located in northern Norway above the Arctic Circle. The impacts of climate change are observed earlier in the Arctic and with more immediate and serious consequences than in most parts of the world (AMAP, 2017; IPCC, 2018). According to Kelton Minor, lead author of the recent Greenland Perspective Survey (Minor et al., 2019), the Arctic is thus "a bellwether for the unequal impact of global warming on social and economic systems" (Minor, cited in McDougall, 2019, paragraph 6). Many Arctic and Greenlandic people are already living in 
regional climates that have been altered by overall warming of more than $1.5^{\circ} \mathrm{C}$ in less than a lifetime (Minor, cited in McDougall, 2019). Considering this pace of change and the severity of Arctic change, such as rising atmospheric and oceanic temperatures, the Norwegian government has identified the Lofoten Islands as being especially vulnerable to climate change (Norwegian Ministry of Climate and Environment, 2015). In 2015 these islands were home to around 24500 people and 892 registered full-time small-scale fishers (Directorate of Fisheries, 2019).

In particular, the historic Lofoten winter cod fisheries and traditional production of the world-famous stockfish, which is Northeast Atlantic (NEA) cod (Gadus morhua) dried on outdoor racks, are vital for settlement and employment structures and the coastal culture. The Lofoten Islands benefit from the warm North Atlantic Current and the resulting rich cod fish stocks and favourable outdoor drying conditions in the winter period from January to April (a perfect mixture of wind, frost, rain and sun), and they are thus the only place in the world where the production of top quality stockfish is possible (Hovelsrud, 2010; interview with the Norwegian Coastal Fishermen's Association, NCFA, in 2015; cf. Sect. 3.2). This traditional stockfish production dates back to the Stone Age and time of the Vikings. Ever since then, the air-dried cod from Lofoten has been a core food and export product. Due to its renowned reputation and strong geographical linkage, it was the first Norwegian quality food product to be awarded the status of Protected Geographical Indication (PGI) in the EU in 2014 (Norwegian "Tørrfisk fra Lofoten"). However, observed and projected climate change impacts risk jeopardising Lofoten's unique position in cod fishery. As a result of ocean temperature increase (according to Fossheim et al., 2015, ${ }^{\circ} \mathrm{C}$ in the Barents Sea from 2004 to 2012; and further temperature rise is projected; cf. IPCC, 2014), a significant northward shift in the NEA cod spawning and feeding locations towards colder waters is likely, which would cause a profound decrease in cod spawning along the Lofoten coast. Another probable threat is that warmer springs would result in flies laying their eggs on the fish drying on outdoor racks and spoil it. Such shifts in cod migration patterns and loss of stockfish quality would especially affect the local fish buyers and fish processors and, above all, the livelihoods of the coastal fishers who operate close to the Lofoten coastline and are not able to access cod fishing grounds offshore and further north due to limited equipment. On average, $80 \%$ of their annual income is derived from catching and selling NEA cod to local fish buyers, which demonstrates the economic and socio-cultural significance of cod fisheries to the local fishing communities (interviews with the Norwegian Coastal Fishermen's Association, NCFA, and coastal fishers in 2015; cf. Sect. 3.2).

\subsection{Empirical data collection}

Our research in both case studies is based on a qualitativeinterpretative approach that focuses on meaning in context and strives for a better understanding of human experiences and practices in the context of climate change (cf. also Bopp, 2020; Bercht, 2019, 2020). In ontological terms, the case study in Tamil Nadu reconciles multiple socially constructed and subjectively perceived realities with the occurrences observable through the researcher's senses (Flick, 2014), which aligns with Cupchik's (2001) constructivist realism. The study aims at eventual theorisation according to grounded theory approaches (Thornberg and Charmaz, 2012). The research approach applied in the Lofoten case study draws on the philosophy of critical realism (Bhaskar, 2008), which holds that reality externally exists but is only accessible through the interpretations of individuals. Accordingly, from an epistemological perspective, an interpretivist design is used in both studies, arguing that scientific knowledge about human behaviour is produced by exploring people's viewpoints in the context of their living conditions. Table 1 provides a more detailed insight into our fieldwork (for more detail cf. Bopp, 2020; Bercht, 2020). We acknowledge that in this paper we provide a rather homogeneous view on the rural Indian and the Norwegian fishing communities where we conducted our fieldwork. However, due to space constraints and the more general aim of promoting a time lens in climate justice debates, we do not further detail the differences between the communities in Tamil Nadu or between the ones on the Lofoten Islands. Moreover, it is important to note that Table 1 is not meant to provide a comparison between the two case studies and the respective fieldwork approaches. Rather, it is intended to briefly summarise the approaches used to further transparency and clarity.

\section{Results and discussion}

Our two case studies revealed particular vulnerabilities to and affectedness by climate change - and thus climate injustices - among the farmers in Tamil Nadu and the coastal fishers on the Lofoten Islands. The local settings and routine practices that these two groups are embedded in are reciprocal with the influence of time. Aspects of time magnify the farmers' and fishers' vulnerabilities in both case studies. Climate injustices consequently result, besides structural drivers of vulnerability, from the farmers' and fishers' handling of and dependence on natural resources for their livelihood, culture and identity. It is not only the availability of water, sun, soil, winds, rains, biodiversity and marine species but also the timely emergence of these that are decisive for the harvest and processing of the produce. The work of food producers and fishers is finely tuned to the pace of their surrounding ecosystems and therefore relies on the functioning and integrity of these. Fluctuations in climatic patterns, as significant as those occurring in recent decades, also shift the 
Table 1. Fieldwork in Tamil Nadu (India) and on the Lofoten Islands (Norway)

\begin{tabular}{|c|c|c|}
\hline & Tamil Nadu (India) & Lofoten Islands (Norway) \\
\hline Methodology & $\begin{array}{l}\text { Inductive, grounded theory, constructivist real- } \\
\text { ism }\end{array}$ & Critical realism, interpretivism \\
\hline Methods & $\begin{array}{l}\text { Open expert interview, go-along interview*; } \\
\text { (participative) observation; informal discus- } \\
\text { sions; action research (e.g. setting up of an or- } \\
\text { ganic community garden in Chennai as part } \\
\text { of observation of the local organic scene); ex- } \\
\text { ploratory mapping; farm visits }\end{array}$ & $\begin{array}{l}\text { Problem-centred, face-to-face interviews with } \\
\text { narrative sequences; participatory observations } \\
\text { (e.g. joining coastal fishers on their fishing trips, } \\
\text { participating in social and cultural gatherings } \\
\text { such as the annual "World Championship in } \\
\text { Cod Fishing" on the Lofoten Islands in March } \\
\text { 2015) }\end{array}$ \\
\hline Period and length of fieldwork & $\begin{array}{l}11 \text { months (April 2017-January 2018, } \\
\text { February-March 2019) }\end{array}$ & $\begin{array}{l}4 \text { months (March 2015, September-December } \\
\text { 2015) }\end{array}$ \\
\hline Recruiting of study participants & $\begin{array}{l}\text { Primary recruiting via existing networks (e.g. } \\
\text { workshop organised by Indo-German Centre } \\
\text { for Sustainability, March 2017); consequent re- } \\
\text { cruiting through key informants in organic food } \\
\text { shops }\end{array}$ & $\begin{array}{l}\text { Recruiting of interview partners through scop- } \\
\text { ing interviews with local key informants (e.g. } \\
\text { from the municipal administration), snowball } \\
\text { sampling (one sample suggests further ones) } \\
\text { and responses to a public call (advertised in the } \\
\text { local newspaper, Lofotposten) }\end{array}$ \\
\hline Data collection & $\begin{array}{l}29 \text { extended expert interviews, informal dis- } \\
\text { cussions (in English or Tamil with transla- } \\
\text { tor; with practising farmers and urban garden- } \\
\text { ers, organic consumers, retailers, trustees of } \\
\text { NGOs (non-governmental organisations) or as- } \\
\text { sociations, governmental officials; documenta- } \\
\text { tion through recording or interview notes); ex- } \\
\text { plorative study and mapping of farming in peri- } \\
\text { urban Chennai; explorative rural farm visits in } \\
\text { southern Tamil Nadu; observation (documenta- } \\
\text { tion through field notes) }\end{array}$ & $\begin{array}{l}43 \text { problem-centred interviews with narrative } \\
\text { sequences (in English) across the Lofoten Is- } \\
\text { lands (e.g. on vessels, in offices), } 31 \text { of which } \\
\text { with current full-time coastal fishers (mostly } \\
\text { lasting between } 2 \text { and } 5 \text { h) and } 12 \text { of which with } \\
\text { fish buyers, processors and suppliers; other lo- } \\
\text { cal residents; environmental charities and or- } \\
\text { ganisations; and representatives from the com- } \\
\text { munities and fisheries officials (e.g. Norwegian } \\
\text { Coastal Fishermen's Association, NCFA, Nor- } \\
\text { wegian "Norges Kystfiskarlag"; except for four } \\
\text { informants, all interviews were recorded) }\end{array}$ \\
\hline Data evaluation & $\begin{array}{l}\text { Verbatim transcription with document analysis, } \\
\text { manual coding through identification of major } \\
\text { themes, no software involved }\end{array}$ & $\begin{array}{l}\text { Transcription and analysis of the interview data } \\
\text { with the assistance of the MAXQDA qualitative } \\
\text { analysis software (coding and identifying major } \\
\text { themes from the interviews) }\end{array}$ \\
\hline
\end{tabular}

* The method of go-along interview allows the researcher to accompany study participants with their usual routines while interviewing them. It allows the researcher to absorb and deepen understanding of the participants' practices in their settings (cf. Kühl, 2016).

farming and fishing practices that have been acquired, transformed and transferred through generations and timed and tailored to the local conditions.

The following sections present and analyse extracts from each case study regarding the way in which aspects of time are contained in the impact of climate injustice on the communities.

\subsection{Discovering aspects of time in the case studies}

\subsubsection{Time and affectedness}

In this section, we pay particular attention to the affectedness of the farmers and coastal fishers by past, recent and potential climate change. By "affectedness" we mean the moment or the state of an event (e.g. a cyclone, a drought or shifting fish migration) and the consequences of that event on the farmers' and fishers' livelihoods and practices. Schlosberg's (2007) and Walker's $(2009,2012)$ three dimensions of distributive and procedural justice and justice of recognition (cf. Sect. 2) may help explain the time aspect in affectedness. Firstly, the farmers' and fishers' geographical locations and socio-structural settings related to these mean they are affected earlier by the repercussions of climate change. Secondly, their affectedness sometimes finds late public and institutional recognition, which can relate to, thirdly, their late consideration in institutional procedures, for example governmental mitigation plans and policies. 
A crucial reality of climate injustices for farmers in Tamil Nadu is their particular susceptibility to climate change owing to their reliance on natural resources. In terms of time, this translates into being among the first groups affected by climate change. This especially applies to smallholders who solely rely on seasonal income received after the harvest of their crops, without having backup resources or alternative business. Farmers who grow one single crop are therefore the most vulnerable, and vulnerability in turn reinforces early affectedness. Figure 1 outlines the different effects (A1, B1 and C1) of climate change on Tamil Nadu smallholders depending on their initial settings (A, B and C; cf. also Sect. 3.1). According to the farmers' observations, their farming setting regarding the environment $(\mathrm{A})$ is being steadily aggravated by the influence of long-term climate change, especially rising surface temperature and great variabilities in the amount of rainfall. Surface temperatures can reach extremes and thereby interfere with the growth of their crops (cf. also Hijioka et al., 2014, p. 1342). This aggravation is further triggered when farmers initiate or increase the use of agrochemicals as an adaptation strategy (A1). Short-term extreme weather events represent extra challenges. In the study area, the smallholders' specific socio-structural and household settings (B and C) determine the eventual effects of and affectedness by both long-term and short-term climate change (B1, $\mathrm{C} 1, \mathrm{~B} 2$ and C2). The farmers' affectedness (B2) is directly influenced by their reactions to climate change such as shifts in farming methods, reduced coping ability or financial restraints (B1 and C1), and vice versa.

To illustrate, a farmer couple in Thiruvannamalai about $200 \mathrm{~km}$ southwest of Chennai, the capital of Tamil Nadu, are representative of early affectedness. At the time of the research visit, rainfall in the rainfed region had been minimal in 2 consecutive years, and the option of groundwater tapping was constrained by repeatedly low groundwater levels (A1). The couple was not able to grow paddy, therefore leaving a large amount of land barren. To maintain a minimum of livelihood, as well as to be able to continue sending their children to college, the couple practised goat rearing and grew a few drought-tolerant crops (B1). The returns are in any case modest (B2 and C2), but the couple's vulnerability is further increased by socio-structural factors. They are indigenous to the area of Thiruvannamalai, and their inherited land is their main resource. Their reliance on regular rains and rice single cropping, the usual practice during non-drought seasons, on the one hand, combines with a lack of investment capacity for water extraction and the class-related deprivation of belonging to an indigenous community, on the other hand ( $\mathrm{A}$, $\mathrm{B}$ and $\mathrm{C}$ ), to convey their salient and early vulnerability.

As our research results indicate, similar to the case of the Indian smallholder farmers, climate change is viewed as a crucial driving force that alters the living conditions of the Lofoten coastal fishers, who are surrounded by and live with and from the ocean. The local weather conditions specifically determine when, how often, for how long and at what risk they may leave the harbours to go out to catch fish at sea (cf. Bercht, 2019, 2020). According to the fishers' observations (cf. also AMAP, 2017), the warming of the ocean is leading to a northward shift of the economically and culturally relevant NEA cod fish stocks and to an increased influx of less valuable southern species such as mackerel and blue whiting. Moreover, a rise of sea level, storms and polar lows negatively affect landing and fish processing facilities, fishing nets left out overnight, weather predictability, and the safety of sea navigation. Facing the accelerating impacts of Arctic climate change, the Lofoten coastal fishers are not only affected earlier and more severely than many other people in the world, but they are also the first to respond and implement strategies to adapt. However, while "early adapters" can provide key lessons for specific adaptation efforts elsewhere (Betzold, 2015), they can hardly make use of or learn from similar past successful adaptations elsewhere or in the place where they live. This is due to the fact that they are the first generation to face the severe consequences of rapid and profound climate change and related uncertainties around scale, intensity and dynamics. For example, as our interview results indicate, no empirical values are yet available for an effective response to a loss of Lofoten stockfish quality (cf. Fig. 2) induced by air temperature and humidity increase and resulting insect infestation and bacterial growth. One could argue that the fishers could build on previous experience with natural climate variability and are thus better prepared to adapt than people who lack such experience. However, this seems not to apply for the interviewed Lofoten fishers. They argue that even though they are used to dealing with (short-term) hazardous conditions at sea and rapid weather changes, they do not know how to efficiently respond to long-term climate impacts and related uncertainties (e.g. northward shift of NEA cod and lack of income).

Given this situation, the urgent question of how to respond and adapt effectively to climate challenges is far from straightforward and likely more difficult for early adapters than it is for more "experienced adapters" who have faced similar climate impacts and already gained skills and knowledge about appropriate adaptation strategies. A crucial challenge for the coastal fishers of being among the first to respond is that best adaptation practices, for example diversifying income structures or changing target fish species, have not yet developed at individual, collective or institutional levels. This lack of "action-oriented guidance" and certainty in action increases the likelihood that the coastal fishers feel overwhelmed and paralysed by fear. For example, instead of dealing with the important but challenging issue of climate adaptation (e.g. talking about one's own perceived helplessness with peers and getting information about adaptation options from peers as a first crucial step towards action), the coastal fishers rather cognitively zone out: "No no, I don't think about climate change because it will be a catastrophe. [... ] I'm very afraid of it" (interview with a fisher on the Lofoten Islands in 2015). This means that the fishers dissociate 


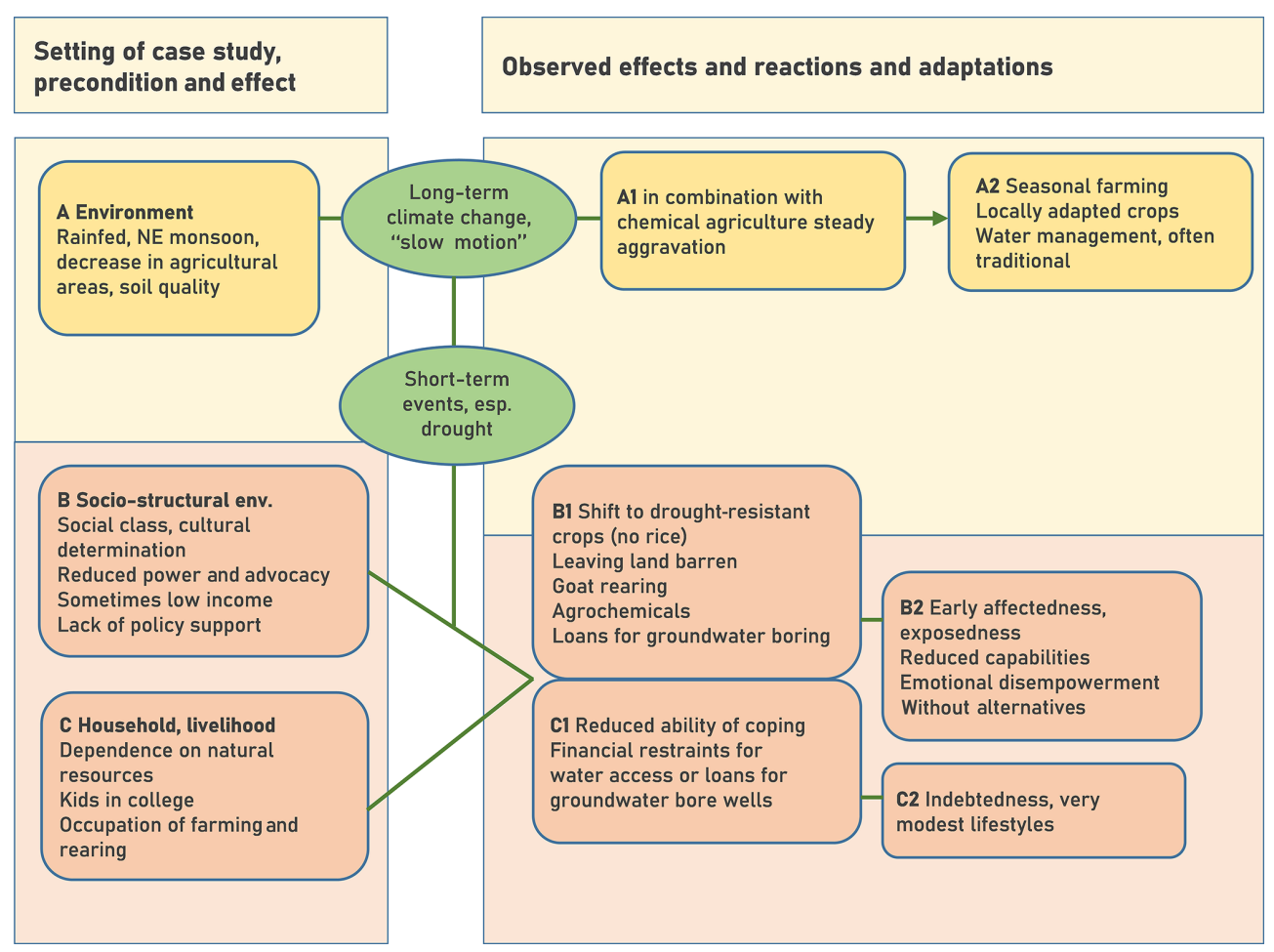

Figure 1. Mapping of climate injustices in the Tamil Nadu case study.
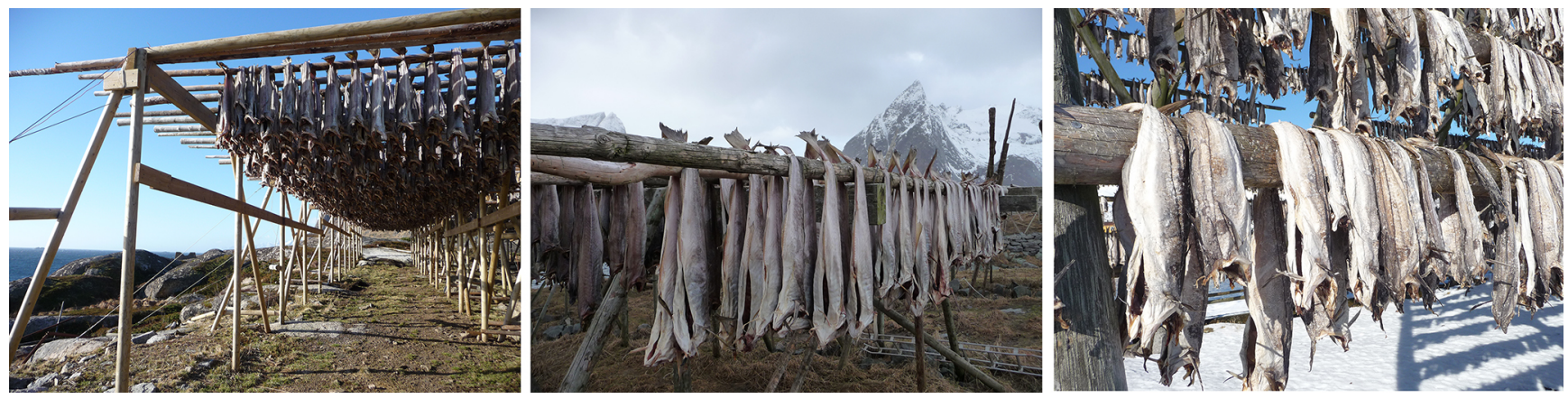

Figure 2. Gutted and de-headed NEA cod drying on outdoor wooden racks on the Lofoten Islands in 2015. The quality of NEA cod is especially threatened by anthropogenic climate change and its impacts on the highly climate-sensitive drying conditions. Photo credit: authors.

themselves from existential threats (e.g. loss of income from cod fisheries) and focus on other issues, such as successfully fighting against oil drilling plans near the biodiversity-rich Lofoten Islands. For instance, the interviewee cited above, who is very afraid of climate change, repeatedly steered the conversation to oil drilling, a topic which he apparently considered easier to talk about: "I' $m$ active in the movement for keeping oil out of Lofoten and Vesteralen. So I try to tell everyone I meet that we have to be careful because hazardous things can happen." Fishers like him try to regulate intolerable emotions (ecoanxiety; cf. below) and protect themselves from a perceived lack of control. Even though "being among the first" opens up opportunities - for example, the first indoor drying facility for NEA cod is being developed on the
Lofoten Islands - the large majority of the coastal fishers feel a lack of orientation, which, in turn, leads to climate inaction rather than to climate action (cf. Bercht, 2019, 2020, for more detail).

\subsubsection{Time, rhythms and rituals}

Rhythm may be broadly defined as a regular repeated pattern of sound or movement. Rhythm can be closely intertwined with rituals, characterised as a sequence of symbolic practices involving gestures, words and objects, often shaped by formality and repetition (Brooks et al., 2016). Ritualised behaviours have subjective meaning beyond their mere actions (Brooks et al., 2016). As Adams (1990; cited in Walker, 
2014 , p. 53) notes, "rhythmicity is the key to the time world of nature", the sun being "the root of all rhythmic organisation". In our case studies, this "time world of nature" (Adams, 1990; cited in Walker, 2014, p. 53) becomes apparent in the rhythmic, sometimes ritualised, organisation of the farmers' and fishers' routines in practising their occupations and organising their private lives, in interaction with their natural environments. It is also through this rhythmic and ritualised organisation that they access the resources their livelihoods are based on. Rhythms and rituals, as part of the place-based identity and culture of communities, are conducive to their social well-being (cf. Adger and Kelly, 1999). Climate change ultimately "threatens cultural dimensions of lives and livelihoods" (Adger et al., 2013, p. 112), which explains the link to climate injustices.

Several study participants in Tamil Nadu narrate the revelation of temporality and ritual in local farming practices, which emerge from natural rhythms and merge with prevalent spiritual-cultural practices. Natural growing cycles typically follow a sequence of preparing the soil, sowing, growing, harvesting and again preparing the soil. Intermediary and cover crops sometimes follow the main crop to favour soil recovery. Some local farmers accord their practice with a traditional solar-based Tamil farming calendar that suggests sequences of crop alteration and rotation. Growing cycles are tuned to the seasons under respective climatic conditions and differ according to each crop variety. Most distinctive is the rice growing cycle, which is often fixed to specific dates.

Beyond that, farmers incorporate routines of worshipping the natural rhythms through rituals such as ceremonies and festivals. Rituals prevail in every step of farming - in the ploughing at the beginning of the season, in the harvesting or in giving "the first harvest of any produce [...] to the local temple", even today where modern technical appliances are used: "they will tie a lemon [...] and [...] bring a coconut in front of the tractor" (interview with an ecologist in Chennai in 2017). As sanctified rituals that pay homage to the entities and the natural resources providing livelihoods, they bring practitioners a feeling of safety. For example, the ritualised sharing of a part of the harvest as "philanthropy" is believed to bring "a bountiful harvest the next time also" (interview with an ecologist in Chennai in 2017). Pongal is an important annual harvesting festival held according to the Tamil calendar. It is "a festival to worship the sun $[\ldots]$ because we need the sun to grow food [...], the essential for farmers" (field notes of the eldest of the organic farming community in Karapettai in 2019).

When climate change modifies the farmers' embodied and ritualised natural rhythms, their practices accordingly need to adapt to new rhythms. While the psychological disorientation occurs rather subtly, many farmers find significant difficulties in adjusting their growing and processing cycles, crop choices, and even marketing strategies. This is often due to being overwhelmed with the new conditions in combination with a lack of adapted methods or capacity, such as time, financial resources, human capital, and mental preparedness.

In contrast to the smallholder farmers, the lives of the Lofoten coastal fishers are strongly shaped by the "rhythm of the ocean" and the resulting dialectic relations between the fishers, other residents of the Lofoten Islands, and their shared broader economic and socio-cultural environments. Like a biological rhythm, every year the NEA cod fish (usually) migrates to the Vestfjord in early spring, is caught and sold to fish producers in spring; is dried outdoors in late spring, spreading the familiar "smell of money" (interview with a local resident on the Lofoten Islands in 2015) around the fishing villages; and is exported to mainland Norway and other countries in June. These regular, repeated patterns of events structure workflows, create meaning, foster group belonging and identification, and are ritually articulated. For instance, the World Championship in Cod Fishing takes place on the Lofoten Islands every year in March to traditionally welcome and celebrate the annual arrival of the NEA cod. School children, dressed up as coastal fishers, meet and sing songs about the history of cod fishing. Tourists also come to join the championships. Another prominent ritual is that children cut off the cod fish's tongue, which is prized as a delicacy. This has been a well-paid and popular holiday job for generations. These examples illustrate that time, rhythms and rituals are intrinsically linked, as time defines rhythms (e.g. when to catch NEA cod) and rituals, and rhythms and rituals give meaning to time (e.g. end and beginning of the fishing season). However, climate change bears the risk of leading to a profound change in rhythms (e.g. northward shift of NEA cod) and rituals that are not only important for social interactions, orienting oneself and making sense of life but also, in a certain figurative sense, for securing the livelihoods and identity of the coastal fishers. Compared to other islanders who are not directly involved in coastal fishing or compared to large-scale fishers who are able to follow the NEA cod offshore, the coastal fishers disproportionately rely on a stable "rhythm of fish migration" (i.e. annual arrival of the NEA cod to the coastline), as this is their main source of income. A time lens helps to uncover or analyse in more depth the unjust impacts of climate change that arise from different dependencies on rhythms and rituals.

\subsubsection{Time and slow motion}

Climatic change can occur suddenly or rather slowly and subtly, as sporadic extreme weather events or climatic patterns in slow conversion. Climate change is not linear but may resemble reversing and proceeding waves. Many of the current great challenges for the global climate impact in slow motion - carbon dioxide emission, glacier melting or sea-level rise, to name a few. Pierrehumbert (2006) states, for example, that global warming will not only add further stress to already hot regions but will also affect freshwater and saltwater fish in the open waters and can evoke agricultural diseases and pest 
outbreaks. He continues to explain that slow-motion changes can be as consequential as sudden climate disasters (Pierrehumbert, 2006).

Tamil Nadu has experienced various sudden extreme weather events in recent years, which have affected the farming sector in particular. Heavy episodic monsoonal rains caused the flooding of plains and agricultural surfaces and overflowed rivers. Cyclones gaining momentum in the Bay of Bengal inflicted damage on vast areas in South India. The effect on the farmers' agricultural fields was twofold in temporal terms. Besides the immediate damage resulting in reduced harvests, compaction and pollution from the debris of the floods lowered the quality of the soils as a side effect (cf. Fig. 1 above). While the events themselves were brief and drastic, the effects are likely to endure and unfold in what may be called "slow motion": the restoration of agricultural soils requires time and skill; wind and floods uproot trees and destroy the roots of crops. Apart from economic loss, farmers in the case study reported how the loss of trees from farm sites and their surrounding areas interacts with the local micro-climates, leading to a reduction in the water retention capacity of soils, rising surface temperatures or crop exposure to direct sunlight. Further dimensions of slow-motion climate change were reported by farmers in Tamil Nadu. These include the slowly rising but menacing aridity of agricultural areas, the slow increase in seasonal fluctuations entailing the degradation of overall farm environments, and farmers' structural deprivations such as reduced water accessibility or agricultural land. Producers accordingly suffer from the "accumulated" temporal effects of climate change, and the resulting injustices link back to the producers' affectedness (cf. "Time and affectedness" above; field notes from 2017 and 2019; for more detail on slow- and rapid-onset disasters see e.g. Fiske and Marino, 2020).

As illustrated earlier, the Lofoten coastal fishers are severely affected by climate change and its slow onset processes, such as sea-level rise and temperature increase. In particular, the higher winter temperatures, the shorter winter seasons and more winter rain already influence the onset and quality of the historic stockfish production. In anticipation of a significant, long-term shift in weather patterns, several fish buyers and processors have started to move their outdoor drying racks further southwest on the islands where outdoor drying conditions are still good enough to produce high-quality stockfish, satisfy demand and maintain local economic stability. However, this (rather short-term) adaptation strategy of relocating drying racks is accompanied by certain economic and socio-cultural drawbacks. For example, such relocation leads to a notable increase in the distance between the (non-movable) fish landing facilities and the drying sites. Consequently, more trucks are required to transport the (fresh and dried) fish back and forth leading to an increase in traffic, costs and time; damage to sensitive road structures; and more nuisance to local residents. Moreover, the drying racks (cf. Fig. 2) are a famous symbol of the Lofoten cod fisheries and hence a tourist attraction; their relocation away from the fishing villages also involves a loss of place in terms of attachment, coastal identity and interest for tourists. Yet, the crucial point here is that the coastal fishers depend on fish buyers and processors who are financially able to buy their landed cod fish. However, the fish buyers and processors, in turn, depend on favourable weather conditions for drying the fishers' landed cod fish. Since the change of weather patterns is happening in slow motion, people see timely ways of adapting their fish production system to the challenges ahead. However, at the same time, strong informative uncertainty still exists regarding the extent of change and the timeframe when a point of no return might be reached (significant decrease in stockfish production). Hence, the residents of the Lofoten Islands feel uncertain about how to efficiently adapt in the long term to the climate threats to stockfish production.

\subsubsection{Time and care}

Our approach to care is deliberately broad in order to explore more openly the contribution of a care point of view to climate justice, a context beyond those in which care is usually addressed. The concept of care, as applied here, is characterised by concern, sense of responsibility, love and affection. Following Barnes (2012) and Held (2006), to take care of somebody or something means to be responsible for their maintenance and well-being; to care for somebody or something is to provide assistance that is needed to help or protect them; and, finally, to care about somebody or something is to be emotionally concerned about their condition, which denotes that somebody or something is important to the person who is caring.

The cultivation of land for agriculture, when it respects the natural farming cycles, can be considered a manner of taking care of the land. This is widely true for the natural farmers ${ }^{1}$ visited throughout the research in Tamil Nadu. By abstaining from any chemical inputs and by adapting their methods to the local environment, they become responsible for ecology and health and indeed view themselves as "caretakers". Care among the natural farmers extends from personal care to care for others (e.g. health of their own families and consumers' health) and for the overall environment (cf. Bopp, 2020). This is reflected in the thinking of a young

\footnotetext{
${ }^{1}$ We purposely refer to both natural and organic farming approaches in our paper. While the underlying methods of both approaches are similar and co-exist, natural farming is preferred by many farmers in the study area. This is also due to the common perception among Indian farmers that the organic farming approach is a Westernised entrepreneurial branch of chemical-free agriculture that aims to achieve organic certification (cf. Bopp, 2020). Some study participants, however, consciously used local concepts and thus identified with the term of natural farming. We use "natural farmers" here in order to respect their voluntary distinction from organic farming. Others instead called themselves organic farmers without any self-categorising intention.
} 
natural farmer in Kanchipuram, explaining natural processes in farming as nourishing humans, animals and nature: "With one grain of rice, you can grow a hundred rice grains. You can feed a person; the cow can be fed with hay; the cow waste becomes fertiliser. [...] The rest of the cycles will be taken care of by nature" (interview with a natural farmer in the district of Kanchipuram in 2018). To the farmers, care means dedication - of extra time, of thought, of responsibility and of emotion. Natural farming systems are said to be time intensive, since they involve manual labour and a holistic understanding of the farming system, in contrast to industrial farming systems that rather follow uni-directional exploitation. The additional time invested is rewarded by the long-term improvement and maintenance of agriculture; care thus receives a quality of foresight.

Other smallholders in the study region embody care through emotional attachment to their occupation and responsibility for their land. A farmer couple in peri-urban Chennai maintain their farm regardless of worsening groundwater availability, drought and the encroaching built-up area. "Being an owner, $[\ldots]$ they are taking care of their farming land. Because recently, lots of companies have been established in this vicinity [...], [but] they don't want to give up on farming" (interview along with a translator with a smallholder couple in Chengalpettu in 2019). Similarly, an elderly farmer in the area continues to farm without making any profit, seeing that if he leaves "the land for a couple of years like this, other plants will cover the area" (interview with an elderly smallholder in Chengalpettu in 2019). Several farming women encountered upon a field trip in a periurban village near Chennai talked of their important role in taking care of farming, assuming the work of their husbands in the fields after the men left to pursue a non-farming occupation to improve the family's livelihood. They reported this trend as common to the case study area. These mostly young women suddenly find themselves in a role requiring a double dedication of time: care for the land in addition to domestic care (i.e. household, children and elderly people) in the absence of their husbands. The unusual workload reflects the time strain experienced by women in such double roles (for aspects of gendered care in resource management cf. e.g. Agarwal, 2000).

Similar to the farmers, the Lofoten case study findings indicate that the fishers interviewed are extremely worried about their future lives, even though their threat appraisals (i.e. considering climate change as a severe threat to their lives as coastal fishers) and emotional reactions (i.e. fear and anxiety caused by threat appraisals) are not always instantly obvious. The fishers are likely to initially deny the seriousness of climate change in order to cope with overwhelming fear and anxiety, for example by reappraising climate impacts as less or non-threatening (cf. Bercht, 2017, 2019, for more detail). However, it is important to stress that the fishers are not deniers but are rather in denial, or, in other words, their coping behaviour represents interpretive but not literal de- nial of climate change. The fishers' concerns are related to concrete harm or loss induced by climate change (e.g. fewer days at sea due to heavier storms and hazardous conditions), uncertainty (e.g. catching fewer NEA cod in the future) and existential threats (underemployment and identity loss). Already they find that they have less planning security with regard to the time when they can catch fish and earn an income, which generates tensions in care-related issues. On the one hand, the fishers wish to take care of and for their partners and families, which includes generating income and dedicating time to their children. On the other hand, in reality, they feel they have less time for their partners and families. This is because, due to the perceived decrease in weather predictability, the fishers also go to the fishing harbours when they cannot go out to the sea (e.g. due to a heavy storm) in order to be able to respond more quickly to weather changes. Moreover, under good weather conditions they stay out at sea as long as they can to catch as many fish as they can because they expect the sea conditions to worsen at any time. A crucial moral problem arises here from conflicting responsibilities and the unsettling dilemma of finding the right balance between spending time with partners and families and spending time on the sea to ensure income stability. More precisely, in this context of care, time becomes a vital resource that is severely challenged by climate change.

\subsubsection{Time and health and well-being}

Climate injustices are often accompanied by direct impacts on the health and well-being of affected groups. By health, we refer to both physical and mental health and are aware of the interrelations of the two. By well-being, we understand an overall state of integral physical and emotional health, which includes living conditions and social relations. A need-based approach suggests four basic needs which conduce to personal well-being, namely feeling "safe and secure", feeling "competent and efficacious", experiencing "relatedness or connection with other people", and feeling "free and autonomous" (Kasser, 2009, p. 175). Risk to health and well-being itself appears through and is often multiplied by the factor of time. As previously explained, climate change differs in scales of time and intensity. Exposure to climate change can therefore result in immediate or potential longterm impacts on health and well-being (cf. Adger and Kelly, 1999). This means that time in our case studies is contained in the farmers' and fishers' health conditions that usually progress on different scales of time and in their early affectedness by climate change which forces many to adopt practices harmful to health.

As outlined by study participants and observed in Tamil Nadu, the health situation of smallholder farmers is as troublesome as worrying, and although there is common awareness of the issue, health statistics do not fully disclose the extent of illness resulting from the sustained and excessive use of agrochemicals. An organic farmer and health activist, 
drawing on his survey of 60 farmer families in a village near Chennai, shared his experience with a flower farmer who applies chemicals twice a week, in order to point out the danger of agrochemicals: "Sir, [...] how did you mix it? 'With my hand'. [...] One is a neurotoxin; one is a carcinogen. [...] If you notice, every single male who sprays [...] [has] hearing defects. [...] All their hands shiver. Whenever he sprays, he can't eat anything that day; [...] the entire body itches" (interview with an organic farmer and health activist in Chennai in 2017). He also stated that many farmers drink and ignore the connection between their health and the chemicals, and "even if there is a connection, 'we have to earn a living for our family", (interview with an organic farmer and health activist in Chennai in 2017). The future outlook is desperate for many farmers - cancer rates and other non-communicable conditions are extraordinarily widespread among chemical farmers and affect especially smallholders whose income often does not allow for adequate medication. The reality of farmer suicides throughout India reflects the accumulation of illness along with the psychological burden of small returns from farming and increasing livelihood pressure (for detail on farmer suicides in India see e.g. Kale et al., 2015; Merriott, 2017). However, the case study also discovered positive experiences of farmers who converted to chemical-free production. A young organic farmer appreciates better health and fewer medical expenses: "I had to spend a lot (INR 4000 per month) for my mother's medical problems. [...] Hence, we started growing [traditional medicine] by ourselves. [...] I realised that eating proper food is the best way to stay healthy" (interview with an organic farmer in Kanchipuram in 2018). And a village-based natural farming community explained how they generate happiness and satisfaction from basing their work on mutual help, which favours their wellbeing (field notes from Karapettai in 2019). The relationship between time and health becomes apparent when it becomes clear that climate change affects vulnerable farmers early and induces them to adopt practices adverse to their health (cf. Sects. 3.1 and 4.1). The heavy and unprotected use of agrochemicals not only entails immediate physical illness and allergies but also affects the farmers' health slowly and steadily. Wider implications are the psychological effects (e.g. depression, anxiety and existential fears) that equally strike farmers over the long term, sometimes preceding their increased use of agrochemicals.

With regard to the relationship between climate change on the Lofoten Islands, time, and the health and well-being of the Lofoten coastal fishers, the empirical results suggest that the fishers are likely to be more vulnerable particularly to the negative mental health effects of climate change than, for example, other residents of the Lofoten Islands (e.g. medical doctors and IT specialists) whose livelihoods are not tied to natural resources. One reason why climate engagement is comparatively low among the fishers (cf. Bercht, 2019, 2020) is that they cannot bear to contemplate the impacts of cli- mate change because they feel too upset and frightened, as discussed above (cf. section on "Time and affectedness").

These results are consistent with the survey findings from the Greenland Perspective Survey (Minor et al., 2019), a nationally representative survey carried out in 2018-2019 of adult Greenlanders ( $n=646$ participants) to investigate their views on environmental changes and Greenland's future in a changing climate. More than one-third of the Greenlanders (38\%) said that they were afraid of climate change.

Drawing on these survey results, Courtney Howard, the board president of the Canadian Association of Physicians for the Environment, confirms that "there is no question Arctic people are now showing symptoms of anxiety, "ecological grief" and even post-traumatic stress related to the effects of climate change" (cited in McDougall, 2019, paragraph 12; cf. also Clayton et al., 2017, on the emerging concept of "ecoanxiety"). Fear and anxiety among the Lofoten coastal fishers stem not from the immediate impact of climate change but from existential threats and uncertainty over what is yet to come (cf. also above). There is currently no indication that mental health issues, such as severe anxiety or depression, prevent fishers from carrying out their fishing activities on a regular basis. Nevertheless, it cannot be ruled out that, in line with Minor et al. (2019) and Clayton et al. (2017), this might change in the future. It can be assumed that "climate anxiety" will play a larger role among the Lofoten coastal fishers, including the extra time and effort needed to cope with it.

The examples from the case studies highlight that the various effects of climate change which provoke climate injustices cannot be thought of without time. Affectedness implies the moment of challenging impact on farmers' and fishers' livelihoods, practices, identities and strategies, which requires a response in the present time and expands into the future. Weather events can determine affectedness at varying scales of velocity. The Lofoten fishers are particularly affected by slow-motion processes such as sea-level rise and temperature increase. In Tamil Nadu, the recent extreme weather events seem more destructive; however heat waves, droughts and monsoon failures, analogously coming about in slow motion, are just as disastrous, although they extend over a longer period.

Similarly, the impacts on the farmers' and fishers' health and well-being can emerge immediately (e.g. allergies, nausea, muscle pain and injuries) or after some time (e.g. cancer, non-communicable disease, depression, anxiety and ecological grief). Rhythms and rituals connect the pace of farmers' and fishers' natural environments and practices. Along with changing climate patterns and seasons, the growing and fishing cycles lose validity and require the practitioners to accord their rhythms and rituals to the new availabilities of natural resources. This can lead to the detaching of their sociocultural identities and the making sense of their lives. Finally, time was ascertained from the farmers' and fishers' practices of care which particularly involve balancing the time spent 


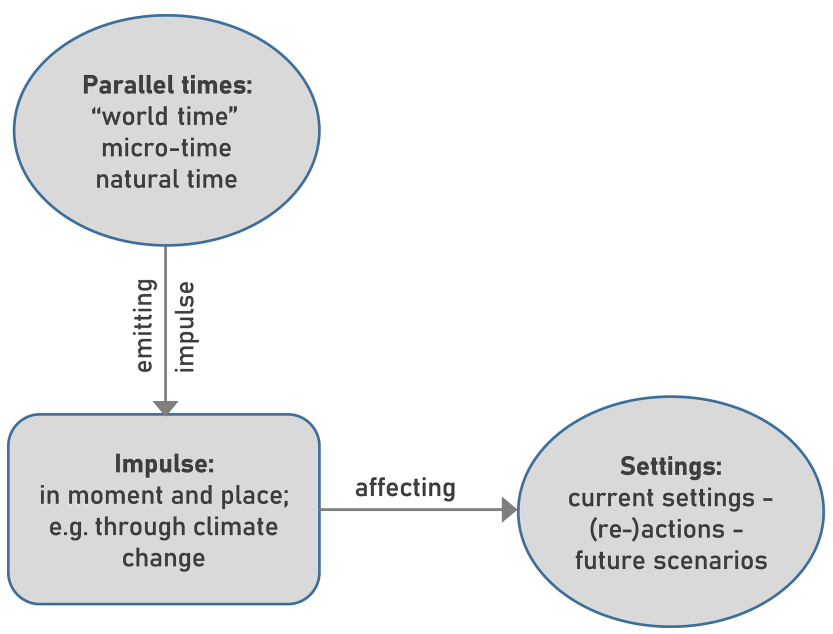

Figure 3. Discovering time in phenomena.

on their occupation with time spent on their families. Adaptation to climate change, however, often demands extra time and unusual workloads.

\subsection{Time in situations of climate injustice}

Based on the concrete aspects of time as above, it makes sense to conceptualise how time influences the farmers' and fishers' lives, practices and affectedness by climate change and finally connects to climate injustices. We therefore now focus on the concepts of impulse and the three forms of time (cf. Sect. 1), as represented in Fig. 3.

One aspect of time lies within the farmers' and fishers' settings (cf. also Fig. 1). These settings are themselves both spatial and temporal (cf. Brace and Geoghegan, 2010), since they refer to the farmers' and fishers' localities under the evolution of time. Another lies in impulse affecting these settings. Impulse may be interpreted as the resonance between entities causing their motion and engendering a reaction when it reaches a body in a certain moment and place. Impulse affects the farmers' and fishers' settings and practices on the one hand and emanates from them on the other. Transferred to our case studies, past and present climate change has given impulse to the farmers' and fishers' environments, their immediate handling of climate change, their adaptation strategies for dealing with it, and finally their future scenarios.

Derived from this understanding, it may be stated that the impulse to the settings, actions and reactions, and future scenarios of our study participants, e.g. through climate change, is embedded in overlapping "parallel times". These times consist of the different paces and timings performed by the various stakeholders and entities of the environment that shape responses to climate change and future scenarios. Thus, the farmers and fishers are connected to the actions of, for example, local authorities, policymakers, traders or consumers. This implies that there is an interplay of actions happening analogously according to the paces and rhythms adopted by the different stakeholders and natural entities.

These parallel times may be described as follows. World time in our case studies represents the paces inherent to the actions of current political stakeholders and to sociocultural scenarios. World time can also allude to the paces existing in norms and moral codes as shaped by the past, in forces of globalisation, in market trends influencing consumer decisions on agricultural and fishery products, and in location-specific regional development. More specific microtime is inherent to the pace and rhythm of the farmers' and fishers' individual practices, routines and rituals on a very local level. Finally, natural time is connected to seasonal patterns, weather and the availability of natural resources. World time, micro-time and natural time notably configure the five dimensions through which time becomes apparent in our case studies. Besides the farmers' and fishers' settings, their handling of climate change is likewise temporal in its present impact and the outcomes that continue into the future. This translates into the current action and the potential of this action that is decisive for whether the situation of the farmers and fishers in our case studies will worsen or improve. The temporality of a present action is hence contained in its future outcome (cf. Winter, 2020). For example, the indigenous smallholder farmer couple in Tamil Nadu (cf. Sect. 4.1) reacted to the enduring water scarcity by temporarily shifting to drought-tolerant chili crops and goat rearing. Their strategy, however, is not conducive to long-term livelihood maintenance because it yields much less income than the usual rice cultivation. It is rather an emergency strategy which is preferable to leaving the land barren because this would mean no income and the risk of their land being overgrown by weeds. Similarly, as our empirical findings suggest, faced with an increase in heavy storms and the related uncertainty of actual time spent fishing (i.e. "soak time"), the Lofoten coastal fishers (especially long-line fishers) expand their daily time at sea to catch as much NEA cod as they can to better bridge (unpredictable) stormy days of no fishing and no income. Yet, as the fishers state, this adaptation strategy of reallocating fishing time is not appropriate on a long-term basis (i.e. months or years), as long days at sea become physically demanding, causing persistent pain (back, neck and shoulders) due to overloading of the body's musculoskeletal system (interview with a fisher on the Lofoten Islands in 2015).

These empirical examples illustrate the importance of using a time lens that sheds light not only on the issues that lead to or foster climate injustices (such as first affectedness) but also on modes of climate adaptation that either enhance, manifest or reduce injustices. In that respect, the theme of parallel times further stresses the insights gained by identifying the different spatio-temporal scales that shape vulnerable communities and the necessity of considering these different scales in adaptational policies. 
4.3

\section{Reflections}

With the help of farmer communities in Tamil Nadu and fisher communities on the Lofoten Islands, it can be seen how climate injustices unfold with respect to time. We have further demonstrated how the communities' settings (e.g. affectedness, health and well-being, and slow motion) that produce these climate injustices and the communities' practices (e.g. rituals and care) exist in and through time, more precisely in and through different parallel times. These insights engender a number of thoughts on the relevance of time in the climate justice discourse as follows.

As previously affirmed for the environmental justice discourse and transferable to climate injustices, "simple spatial analyses" (Agyeman et al., 2016, p. 327) are no longer able to do justice to the complex scales of contemporary inequalities resulting from vulnerability to climate change (cf. also Walker, 2009). Instead, following Brace and Geoghegan (2010), climate justice research would benefit from responding to "questions of scale" (p. 296) that span a range of spatial and temporal aspects. Referring to the scale argument, Brace and Geoghegan (2010) point out that climate change is too often seen as a global and deterministic problem. This still holds today, as the latest IPCC reports suggest. It follows that climate research has often been detached from the social, political and individual contexts leading to and shaping climate change. What is thus needed in addition to a global-scale perspective is a more grounded approach that addresses climate change and temporalities on a local level. If we realise the relational character of climate change, we can emotionally grasp it and recognise it on a local level as part of our "fabric of everyday life" (Brace and Geoghegan, 2010 , p. 284) that extends over past, present and future generations (Reder et al., 2018; Winter, 2020). While time is not commonly thought of as part of space, the case studies show that time and space are interwoven in people's everyday practices of facing climate change.

The continuous spatio-temporal shaping of settings and practices of the farmers and fishers occur under three facets of time, world time, micro-time and natural time (cf. Sect. 4.2), which give impulses at their own paces. Thinking in terms of deriving actions with future impact means elaborating the possible (or urgent) measures for future scenarios according to the settings that affected groups face at present. This implies that the timeliness with which adaptation measures are implemented is crucial in determining the persistence of or relief from (unjust) affectedness by climate change. It also shows that time is crucial to people's capabilities to detect and react to climate injustices; to the coping strategies and concrete adaptation measures of affected groups; and, further, to political responses to pre-empt or mitigate crises, for example policies and regulations.

The link between space, time and the affectedness of vulnerable groups clearly lies in their unequal exposure to climate change risk. Smallholders in rainfed regions and coastal fishers at sea level are and will be affected by rising global temperatures, fluctuating natural resources and altering seasons earlier than groups in lower-risk areas. Climate injustices to the farmers and fishers unfold as existential fears and livelihood pressures, health stress, and emotional distress that are likely to be aggravated by the persistence of climate change challenges of the current extent. Consequently, their needs have more urgency. The concept of (geographical) proximity (for more cf. Walker, 2009) may need to be widened from its focus on spatiality to include temporality and therefore the concepts of exposedness to risk or of vulnerability.

Tackling climate injustices is a serious challenge that needs to recognise these spatio-temporalities to be able to create adequate strategies for swift and timely implementation. It is necessary to embrace the "time lags" that draw on the locally distinct rhythms of stakeholders and patterns of "being climate", since all produce "climate-time" (Neimanis and Walker, 2014, p. 558).

Local adaptive strategies often differ significantly, and the local knowledge of vulnerable groups can be momentous resources for adaptation. The farmers' and fishers' professional and emotional connectedness with natural resources often permits their excellent observation of climatic patterns and ecological imbalances. This not only reveals the validity of practitioners' knowledge but also stresses its potential benefit on a policy level. For this reason, the narratives of how, where and when vulnerable groups experience climate change are vital to the understanding of affectedness and should complement the scientific discourses.

\section{Conclusions}

The intention of this paper is to inspire readers to see climate, its changes and invoked injustices, as well as future climate scenarios, as being organically shaped through and with the spatio-temporalities of practices. Considering the dimension of time has several benefits for climate justice research and practice. Firstly, it facilitates a deeper understanding of aspects leading to and fostering climate injustices. The temporal embeddedness of the settings of vulnerable people and their measures in reaction to climate change opens a dimension beyond the spatial, socio-cultural or socio-political dimension that climate justice scholarship has mostly focused on. A time lens can make climate injustices visible that otherwise remain untackled and unresolved. Secondly, recognition of the temporal embeddedness of settings helps reveal the affectedness of vulnerable people by climate change in more detail. This, in turn, is crucial to the acknowledgement of inequalities and injustices and relates to procedural justice, namely institutional responses in the pre-emption or mitigation of crises, for example through policies and regulations. And, thirdly, adaptation and resilience strategies require the implication of time aspects in order to be timely. While all 
adaptation and resilience measures are urgent, some have priority. The inclusion of aspects of time offers an alternative way of engaging with climate change as something each of us actively experiences and lives (cf. Neimanis and Walker, 2014). As an important insight, qualitative scenarios based on the different facets of time as perceived by local groups can be a valuable complement to existing quantifications of climate change projections. Although undeniably important to visualising climatic trends, an overly quantified presentation risks remaining "relatively deterministic" (Brace and Geoghegan, 2010, p. 297) and difficult to relate to from the general public's perspective. Qualitative scenarios require, as our case studies indicate, the contemplation of narratives of climate injustices and how these emerge from the typical local settings and the farmers' and fishers' ways of "weathering" the situation (Neimanis and Walker, 2014, p. 570). Humans engage with climate and shape it through their own metabolisms. Greater personal relatedness to climate change, i.e. understanding our own "intra-active" (Neimanis and Walker, 2014, p. 560; cf. Introduction) experiences or our embodiments of climate change, may aid our solidarity with vulnerable groups. Identification with our active co-producing of climate through our own practices may favour a willingness to address issues of climate injustices in accordance with our individual capacities.

Data availability. The qualitative research data for this paper were collected under guarantees that they would be only used for the purpose of research and associated publication. Confidentiality considerations mean that the qualitative data cannot be made available for public access. Any queries regarding data and their interpretation should be directed to the authors.

Author contributions. JB and ALB contributed equally to developing the ideas presented in this paper. JB took the lead in writing the paper.

Competing interests. The authors declare that they have no conflict of interest.

Acknowledgements. We would like to thank all study participants in Tamil Nadu and on the Lofoten Islands who generously gave their time to participate in our research. We also wish to express our gratitude to our editor and two anonymous reviewers for their continued support and valuable comments. We gratefully acknowledge the generous financial support by the Indo-German Centre for Sustainability (IGCS) and the Fritz Thyssen Foundation.

Financial support. This research has been supported by the IndoGerman Centre for Sustainability (IGCS) (postdoctoral scholarship) and the Fritz Thyssen Foundation (grant no. Az. 20.14.0.100).
Review statement. This paper was edited by Jonas Hein and reviewed by two anonymous referees.

\section{References}

Adger, W. N. and Kelly, P. M.: Social Vulnerability to Climate Change and the Architecture of Entitlements, Mitig. Adapt. Strat. Gl., 4, 253-266, https://doi.org/10.1023/A:1009601904210, 1999.

Adger, W. N., Barnett, J., Brown, K., Marshall, N., and O'Brien, K.: Cultural dimensions of climate change impacts and adaptation, Nat. Clim. Change, 3, 112-117, https://doi.org/10.1038/nclimate1666, 2013.

Agarwal, B.: Conceptualising environmental collective action: why gender matters, Camb. J. Econ., 24, 283-310, https://doi.org/10.1093/cje/24.3.283, 2000.

Agyeman, J., Schlosberg, D., Craven, L., and Matthews, C.: Trends and Directions in Environmental Justice: From Inequity to Everyday Life, Community, and Just Sustainabilities, Annu. Rev. Environ. Resour., 41, 321-340, https://doi.org/10.1146/annurevenviron-110615-090052, 2016.

AMAP (Arctic Monitoring and Assessment Programme): Adaptation Actions for a Changing Arctic (AACA), Barents Area Overview Report, AMAP, Oslo, 2017.

Arnall, A. and Kothari, U.: Challenging climate change and migration discourse: Different understandings of time-scale and temporality in the Maldives, Global Environ. Change, 31, 199-206, https://doi.org/10.1016/j.gloenvcha.2015.01.011, 2015.

Atmanspacher, H. and Ruhnau, E.: Introduction Remarks, in: Time, Temporality, Now: Experiencing Time and Concepts in an Interdisciplinary Perspective, edited by: Atmanspacher, H. and Ruhnau, E., Springer, Berlin, Heidelberg, Germany, 1-4, 1997.

Balasubramanian, A. V.: A hand to the plough: We need an alternative approach to farming that builds on indigenous knowledge and resources, Financial Chronicle, available at: http://ciks.org/ old-site/Ahandtotheplough-AVBalasubramanian19-05-15.pdf (last access: 13 January 2021), 2015.

Bardon, A. and Dyke H. (Eds.): A Companion to the Philosophy of Time, Wiley-Blackwell, Chichester, 2013.

Barnes, M.: Care in Everyday Life: An Ethic of Care in Practice, The Policy Press, Bristol, 2012.

Bercht, A. L.: Tackling climate inaction: How a social identity approach matters to climate communication. Ideas how to communicate differently. Long version, Wissenschaftsmanagement Open Access, Berlin, Bonn, 2020.

Bercht, A. L.: Sleepwalking into disaster? Understanding coping in the broader field of mental barriers. Examples from the Norwegian Arctic in the face of climate change, in: Disaster Research and the Second Environmental Crisis: Assessing the Challenges Ahead, edited by: Kendra, J., Knowles, S. G. , and Wachtendorf, T., Springer, New York, 137-160, 2019.

Bercht, A. L.: Stress, emotions and coping in Guangzhou, China, Human-environment-transactions from a geographical and psychological perspective, Megacities and Global Change Vol. 8, Franz Steiner Verlag, Stuttgart, 2013.

Bercht, A. L.: No climate change salience in Lofoten fisheries? A comment on understanding the need for adaptation in natural resource dependent communities, Clim. Change, 144, 565-572, https://doi.org/10.1007/s10584-017-2061-6, 2017. 
Betzold, C: Adapting to climate change in small island developing states, Clim. Change, 133, 481-489, https://doi.org/10.1007/s10584-015-1408-0, 2015.

Bhaskar, R.: A Realist Theory of Science, With a New Introduction, Routledge, London, 2008.

Bopp, J.: Local Notions of Alternative Practices: Organic Food Movements in Bangkok, Thailand and Chennai, India, Sustainability, 12, 1952, https://doi.org/10.3390/su12051952, 2020.

Brace, C. and Geoghegan, H.: Human geographies of climate change: Landscape, temporality, and lay knowledges, Prog. Hum. Geog., 35, 284-302, https://doi.org/10.1177/0309132510376259, 2010.

Brann, E. T. H.: What, Then, is Time?, Rowman \& Littlefield Publishers, Boston, 1999.

Brooks, A. W., Schroeder, J., Risen J. L., Gino, F., Galinsky, A. D., Norton, M. I., and Schweitzer, M. E.: Don't stop believing: Rituals improve performance by decreasing anxiety, Organ. Behav. Hum. Dec., 137, 71-85, https://doi.org/10.1016/j.obhdp.2016.07.004, 2016.

Caney, S.: Cosmopolitan Justice, Rights and Global Climate Change, Can. J. Law. Jurisprud, 2006, 19, 255-278, https://doi.org/10.1017/S0841820900004100, 2006.

Census 2011: States Census 2011, available at: http://www. census2011.co.in/states.php, last access: 23 March 2020.

Clayton, S., Manning, C. M., Krygsman, K., and Speiser, M.: Mental Health and Our Changing Climate: Impacts, Implications, and Guidance, American Psychological Association, and ecoAmerica, Washington, D.C., 2017.

Cupchik, G.: Constructivist Realism: An Ontology That Encompasses Positivist and Constructivist Approaches to the Social Sciences, Forum Qualitative Sozialforschung/Forum: Qualitative Social Research, 2, 7, https://doi.org/10.17169/fqs-2.1.968, 2001.

Directorate of Fisheries: Data from register of Norwegian fishermen, available at: https://www.fiskeridir.no/English/Fisheries/ Statistics/Fishermen-fishing-vessels-and-licenses (last access: 21 March 2020), 2019.

ENVIS (Environmental Information System) Centre: Tamil Nadu 2018: Climate, available at: http://tnenvis.nic.in/Database/ Climat_1209.aspx (last access: 23 March 2020), 2018.

ENVIS (Environmental Information System) Centre: Tamil Nadu 2020: Agriculture, available at: http://tnenvis.nic.in/Database/ TN-ENVIS_792.aspx, last access: 15 July 2020.

Feng, X., Porporato, A., and Rodriguez-Iturbe, I.: Changes in rainfall seasonality in the tropics, Nat. Clim. Change 3, 811-815, https://doi.org/10.1038/nclimate1907, 2013.

Fiske, S. J. and Marino, E.: Slow-Onset Disaster: Climate Change and the Gaps between Knowledge, Policy and Practice, in: Disaster upon Disaster. Exploring the Gap between Knowledge, Policy, and Practice, edited by: Hoffmann, S. and Barrios, R. E., Berghahn, New York, Oxford, 139-171, 2020.

FitzGerald, F. G., Capon, A., and Aitken, P.: Resilient health systems: preparing for climate disasters and other emergencies, Med. J. Australia, 210, 304-305, https://doi.org/10.5694/mja2.50115, 2019.

Flick, U. (Ed.): An introduction to qualitative research. Sage, Los Angeles, London, New Delhi, Singapore, Washington, D.C., 2014.
Fossheim, M., Primicerio, R., Johannesen, E., Ingvaldsen, R., Aschan, M., and Dolgov, A.: Recent warming leads to a rapid borealization of fish communities in the Arctic, Nat. Clim. Change, 5, 673-678, https://doi.org/10.1038/NCLIMATE2647, 2015.

Fünfgeld, H. and Schmid, B.: Justice in climate change adaptation planning: conceptual perspectives on emergent praxis, Geogr. Helv., 75, 437-449, https://doi.org/10.5194/gh-75-4372020, 2020.

Gach, E.: Normative Shifts in the Global Conception of Climate Change: The Growth of Climate Justice, Soc. Sci., 8, 24, https://doi.org/10.3390/socsci8010024, 2019.

Gardiner, S. M.: Climate Justice, in: The Oxford Handbook of Climate Change and Society, edited by: Dryzek, J. S., Norgaard, R. B., and Schlosberg, D., Oxford University Press, Oxford, 309322, 2011.

Government of Tamil Nadu - Department of Evaluation and Applied Research: Tamil Nadu - An Economic Appraisal 201112 to 2013-14: Agriculture, available at: https://www.tn.gov.in/ dear/, last access: 23 March 2020.

Grosz, E.: The Nick of Time: Politics, Evolution and the Untimely, Duke University Press, Durham, London, 2004.

Gumo, S.: Praying for Rain: Indigenous Systems of Rainmaking in Kenya, Ecumenical Rev., 69, 386-397, https://doi.org/10.1111/erev.12301, 2017.

Hastrup, K. and Robow, C.: Introduction, in: Living with environmental change, Waterworlds, edited by: Hastrup, K. and Robow, C., Routledge, London, New York, 2-9, 2014a.

Hastrup, K. and Robow, C.: Living with environmental change, Waterworlds, Routledge, London, New York, 2014b.

Hatfield, C. S., Marino, E., Whyte, K. P., Dello, K. D., and Mote, P. W.: Indian time: time, seasonality, and culture in Traditional Ecological Knowledge of climate change, Ecol. Process, 7, 111, https://doi.org/10.1186/s13717-018-0136-6, 2018.

Held, V.: The Ethics of Care, in: The Oxford Handbook of Ethical Theory, edited by: Copp, D., Oxford University Press, New York, 537-566, 2006.

Hijioka, Y., Lin, E., Pereira, J. J., Corlett, R. T., Cui, X., Insarov, G. E., Lasco, R. D., Lindgren, E., and Surjan, A.: Asia, in: Climate Change 2014: Impacts, Adaptation, and Vulnerability. Part B: Regional Aspects. Contribution of Working Group II to the Fifth Assessment Report of the Intergovernmental Panel on Climate Change, edited by: Barros, V. R., Field, C. B., Dokken, D. J., Mastrandrea, M. D., Mach, K. J., Bilir, T. E., Chatterjee, M., Ebi, K. L., Estrada, Y. O., Genova, R. C., Girma, B., Kissel, E. S., Levy, A. N., MacCracken, S., Mastrandrea, P. R., and White, L. L., Cambridge University Press, Cambridge, United Kingdom and New York, NY, USA, 1327-1370, 2014.

Holland, B.: Procedural justice in local climate adaptation: political capabilities and transformational change, Environ. Polit., 26, 391-412, https://doi.org/10.1080/09644016.2017.1287625, 2017.

Hovelsrud, G. K., Dannevig, H., West, J., and Amundsen, H.: Adaptation in Fisheries and Municipalities: Three Communities in Northern Norway, in: Community Adaptation and Vulnerability in Arctic Regions, edited by: Hovelsrud, G. K. and Smit, B., Springer, Dordrecht, 23-62, 2010.

Hutchison, E. D.: Dimensions of Human Behavior, Person and Environment, Fifth Edition, Sage Publications, Thousand Oaks, 2015. 
IPCC (International Panel on Climate Change): Climate Change 2014: Impacts, Adaptation, and Vulnerability, Part A: Global and Sectoral Aspects, Contribution of Working Group II to the Fifth Assessment Report of the Intergovernmental Panel on Climate Change, Cambridge University Press, Cambridge, New York, 2014.

IPCC (International Panel on Climate Change): Global Warming of $1.5^{\circ} \mathrm{C}$. An IPCC Special Report on the impacts of global warming of $1.5^{\circ} \mathrm{C}$ above pre-industrial levels and related global greenhouse gas emission pathways, in the context of strengthening the global response to the threat of climate change, sustainable development, and efforts to eradicate poverty, IPCC, Cambridge, 2018.

Kale, N. M., Dani, R. G., and Mankar, D. M.: Approaches for ending the era of farmer's suicides, J. Agr. Sci., 28, 137-141, 2015.

Kasser, T.: Psychological Need Satisfaction, Personal Well-Being, and Ecological Sustainability, Ecopsychology, 1, 175-180, https://doi.org/10.1089/eco.2009.0025, 2009.

Kühl, J.: Walking Interviews als Methode zur Erhebung alltäglicher Raumproduktion, Europa Regional, 23, 35-48, 2016 (in German).

Lefebvre, H. and Régulier, C.: Le projet rythmanalytique, Communications, 41, 191-199, https://doi.org/10.3406/comm.1985.1616, 1985 (in French).

McDougall, D.: "Ecological grief": Greenland residents traumatised by climate emergency, available at: https://www.theguardian.com/world/2019/aug/12/ greenland-residents-traumatised-by-climate-emergency (last access: 20 March 2020), 2019.

Meister, J. C. and Schernus, W.: Time. From Concept to Narrative Construct: A Reader, De Gruyter, Berlin, Boston, 2011.

Merriott, D.: Factors associated with the farmer suicide crisis in India, J. Epidemiol. Global H., 6, 217-227, https://doi.org/10.1016/j.jegh.2016.03.003, 2017.

Meyer-Ohlendorf, L.: Drivers of Climate Change in Urban India. Social Values, Lifestyles, and Consumer Dynamics in an Emerging Megacity, Springer, Cham, 2019.

Minor, K., Agneman, G., Davidsen, N., Kleemann, N., Markussen, U., Olsen, A., Lassen, D., and Rosing, M. T.: Greenlandic Perspectives on Climate Change 2018-2019. Results from a National Survey, University of Greenland and University of Copenhagen. Kraks Fond Institute for Urban Research, Aalborg, Copenhagen, Danemark, 2019.

Neimanis, A. and Walker, R. L.: Weathering: Climate Change and the "Thick Time" of Transcorporeality, Hypatia, 29, 558-575, https://doi.org/10.1111/hypa.12064, 2014.

Newell, P., Srivastava, S., Naess, L. O., Torres Contreras, G. A., and Price, R.: Towards Transformative Climate Justice: Key Challenges and Future Directions for Research, Working Paper Vol. 2020, Nr. 540, Institute of Development Studies, Brighton, 2020.

Nightingale, A. J., Eriksen, S., Taylor, M., Forsyth, T., Pelling, M., Newsham, A., Boyd, E., Brown, K., Harvey, B., Jones, L., and Bezner Kerr, R.: Beyond Technical Fixes: climate solutions and the great derangement, Clim. Dev., 12, 343-352, https://doi.org/10.1080/17565529.2019.1624495, 2020.

Norwegian Ministry of Climate and Environment: Update of the integrated management plan for the Barents Sea - Lofoten area including an update of the delimitation of the marginal ice zone.
Meld. St. 20 (2014-2015) Report to the Storting (white paper), Norwegian Ministry of Climate and Environment, Oslo, 2015.

O'Brien, K.: Global environmental change II. From adaptation to deliberate transformation, Prog. Hum. Geog., 36, 667-676, https://doi.org/10.1177/0309132511425767, 2012.

Oppermann, E., Walker, G., and Brearley, M.: Assembling a thermal rhythmanalysis: Energetic flows, heat stress and polyrhythmic interactions in the context of climate change, Geoforum, 108, 275285, https://doi.org/10.1016/j.geoforum.2019.09.012, 2020.

Pahl, S., Sheppard, S., Boomsma, C., and Groves, C.: Perceptions of time in relation to climate change, WIRES Clim. Change, 5, 375-388, https://doi.org/10.1002/wcc.272, 2014.

Pierrehumbert, R. T.: Climate Change: A Catastrophe in Slow Motion, Chic. J. Int. Law, 6, 573-596, 2006.

Pilkey, O. H. and Pilkey. K. C.: Sea Level Rise: A Slow Tsunami on America's Shores, Duke University Press, Durham, London, 2019.

Reder, M., Tamoudi, N., and Faets, S.: Fresh Perspectives on Intergenerational Justice: Comments on Social Criticism, Temporality, and Future Narratives, in: Jahrbuch praktische Philosophie in globaler Perspektive//Yearbook Practical Philosophy in a Global Perspective: Schwerpunktthema: Natur als Bezugspunkt der praktischen Philosophie, 1. Auflage, edited by: Reder, M., Filipovic, A., Finkelde, D., and Wallacher, J., Jahrbuch Praktische Philosophie in globaler Perspektive, 2, Alber, Freiburg im Breisgau, 279-304, 2018.

Schlosberg, D.: Defining Environmental Justice: Theories, Movements, and Nature, Oxford University Press, Oxford, 2007.

Schlosberg, D. and Collins, L. B.: From environmental to climate justice: Climate change and the discourse of environmental justice, WIRES Clim. Change, 5, 359-374, https://doi.org/10.1002/wcc.275, 2014.

Tamil Nadu Climate Change Knowledge Portal: Yearly Temperature in Tamil Nadu temporarily, available at: http://tnsccc.in/ max-temperature.php, last access: 12 December 2020.

Tamoudi, N. and Reder, M.: A narrative account of temporality in climate justice, in: Routledge handbook of climate justice, edited by: Jafry, T., Mikulewicz, M., and Helwig, K., Routledge handbooks, Routledge, London, New York, NY, 57-67, 2019.

Thornberg, R. and Charmaz, K.: Grounded Theory, in: Qualitative research: An introduction to methods and designs, edited by: Lapan, S. D., Quartaroli, M. T., and Riemer, F. J., Research Methods for the Social Sciences, Jossey-Bass, San Francisco, Calif., 41-68, 2012.

Van Loon, A. F., Tijdeman, E., Wanders, N., Van Lanen, H. A. J., Teuling, A. J., and Uijlenhoet, R.: How climate seasonality modifies drought duration and deficit, J. Geophys. Res.-Atmos., 119, 4640-4656, https://doi.org/10.1002/2013JD020383, 2014.

Walker, G.: Beyond Distribution and Proximity: Exploring the Multiple Spatialities of Environmental Justice, Antipode, 41, 614636, https://doi.org/10.1111/j.1467-8330.2009.00691.x, 2009.

Walker, G.: Environmental Justice: Concepts, Evidence and Politics, Routledge, London, 2012.

Walker, G.: The dynamics of energy demand: Change, rhythm and synchronicity, Energy Res. Soc. Sci., 1, 49-55, https://doi.org/10.1016/j.erss.2014.03.012, 2014.

Watts, N., Adger, W. N., Agnolucci, P., Blackstock, J., Byass, P., Cai, W., Chaytor, S., Colbourn, T., Collins, M., Cooper, A., Cox, P. M., Depledge, J., Drummond, P., Ekins, P., Galaz, V., Grace, 
D., Graham, H., Grubb, M., Haines, A., Hamilton, I., Hunter, A., Jiang, X., Li, M., Kelman, I., Liang, L., Lott, M., Lowe, R., Luo, Y., Mace, G., Maslin, M., Nilsson, M., Oreszczyn, T., Pye, S., Quinn, T., Svensdotter, M., Venevsky, S., Warner, K., Xu, B., Yang, J., Yin, Y., Yu, C., Zhang, Q., Gong, P., Montgomery, H., and Costello, A.: Health and climate change: Policy responses to protect public health, Lancet, 386, 1861-1914, https://doi.org/10.1016/S0140-6736(15)60854-6, 2015.
White, R.: Controversies in Environmental Sociology, Cambridge University Press, Cambridge, 2004.

Winter, C. J.: Does time colonise intergenerational environmental justice theory?, Environ. Politics, 29, 1-19, https://doi.org/10.1080/, 2020. 